\title{
Non-adherence to inhaled corticosteroids and the risk of asthma exacerbations in children
}

\author{
This article was published in the following Dove Press journal: \\ Patient Preference and Adherence \\ 12 April 2016 \\ Number of times this article has been viewed
}

\author{
Erwin C Vasbinder ${ }^{1}$ \\ Svetlana $\vee$ Belitser ${ }^{2}$ \\ Patrick C Souverein ${ }^{2}$ \\ Liset van Dijk ${ }^{3}$ \\ Arnold G Vulto' \\ Patricia MLA van den Bemt ${ }^{\prime}$ \\ 'Erasmus University Medical \\ Center, Department of Hospital \\ Pharmacy, Rotterdam, ${ }^{2}$ Division \\ of Pharmacoepidemiology and Clinical \\ Pharmacology, Utrecht Institute for \\ Pharmaceutical Sciences, Utrecht \\ University, ${ }^{3} \mathrm{NIVEL}$, Utrecht, \\ the Netherlands
}

Background: Non-adherence to inhaled corticosteroids (ICSs) is a major risk factor for poor asthma control in children. However, little is known about the effect of adherence to ICS on the incidence of asthma exacerbations. The objective of this study was to examine the effect of poor adherence to ICS on the risk of exacerbations in children with asthma.

Methods: In this nested case-control study using data from the Dutch PHARMO Record Linkage System, children aged 5-12 years who had an asthma exacerbation needing oral corticosteroids or hospital admission were matched to patients without exacerbations. Refill adherence was calculated as medication possession ratio from ICS-dispensing records. Data were analyzed using a multivariable multiplicative intensity regression model.

Results: A total of 646 children were included, of whom 36 had one or more asthma exacerbations. The medication possession ratio was $67.9 \%$ (standard deviation [SD] 30.2\%) in children with an exacerbation versus $54.2 \%$ (SD 35.6\%) in the control group. In children using long-acting beta-agonist, good adherence to ICS was associated with a higher risk of asthma exacerbations: relative risk 4.34 (95\% confidence interval: 1.20-15.64).

Conclusion: In children with persistent asthma needing long-acting beta-agonist, good adherence to ICS was associated with an increased risk of asthma exacerbations. Possible explanations include better motivation for adherence to ICS in children with more severe asthma, and reduced susceptibility to the consequences of non-adherence to ICS due to overprescription of ICS to children who are in clinical remission. Further study into the background of the complex interaction between asthma and medication adherence is needed.

Keywords: asthma exacerbation, children, database, inhaled corticosteroids, refill adherence pharmacoepidemiology, observational study, the Netherlands

\section{Introduction}

Asthma is the most common chronic disease seen in children in the Western world, with an estimated prevalence of 5\%-10\%. ${ }^{1,2}$ Inhaled corticosteroids (ICSs) have an important place in asthma therapy and is prescribed when asthmatic symptoms cannot be sufficiently controlled by short-acting beta-agonist (SABA) alone. The aim of ICS treatment is reaching and maintaining good asthma control, which is characterized by a low frequency and severity of asthma symptoms, no limitation of physical activities, and a limited need for reliever/rescue treatment with SABA. ${ }^{2}$ In clinical trials, ICS has proved to be effective, reducing exacerbations by $55 \%$ compared to placebo or SABA alone. ${ }^{3}$ However, more than half of the childhood population (6-16 years) with doctor-diagnosed asthma has insufficient control according to the Global Initiative for Asthma (GINA) recommendations. ${ }^{4}$ As a result of poor asthma control, asthma exacerbations needing hospitalization occur with an estimated incidence of one to two per 1,000 child-years (data from the USA). ${ }^{5,6}$
Correspondence: Patricia MLA van den Bemt

Erasmus University Medical Center, Department of Hospital Pharmacy,

Nc-2I2, PO Box 2040, 3000 CA

Rotterdam, the Netherlands

Tel +31107033202

Fax +31 107032400

Email p.vandenbemt@erasmusmc.nl
Patient Preference and Adherence 2016:10 53।-538

Dovepres:

http://dx.doi.org/10.2147/PPA.S92824 (c) (7) (5) 2016 Vasbinder et al. This work is published and licensed by Dove Medical Press Limited. The full terms of this license are avalable at https://www.dovepress.com/terms.php cc. ${ }_{\mathrm{BY}} \mathrm{NC}$ and incorporate the Creative Commons Attribution - Non Commercial (unported, v3.0) License (http://(creativecommons.org/licenses/by-n/ 3.00 ). By accessing the work you hereby accept the Terms. Non-commercial uses of the work are permitted without any further permission from Dove Medical Press Limited, provided the work is properly attributed. For permission for commercial use of this work, please see paragraphs 4.2 and 5 of our Terms (https://www.dovepress.com/terms.php). 
Risk factors for poor asthma control include poor socioeconomic status and ethnic minority affiliation, ${ }^{7-9}$ young age, ${ }^{6}$ parental smoking, ${ }^{10}$ negative parental perceptions about medication, ${ }^{11}$ and exposure to allergens, pollutants, and viral infections. ${ }^{2} \mathrm{~A}$ critical factor for maintaining good asthma control seems adherence to ICS treatment, which ranges from $40 \%$ to $70 \%$ in children. ${ }^{12-14}$ In a study among 102 children, adherence to ICS was $17 \%$ higher in patients with controlled asthma than in those with uncontrolled asthma $(P<0.001) .{ }^{15} \mathrm{~A}$ similar result was reported in a recent study in 81 Dutch children which showed a trend of higher levels of asthma control with higher levels of adherence to $\operatorname{ICS}(P=0.028) .{ }^{16}$

Although the effect of adherence to ICS on asthma control is generally positive, conflicting evidence exists on the occurrence of episodes of very poorly controlled asthma: asthma exacerbations, needing a short course of oral corticosteroids, or hospital admission in children. A recent systematic review reported that high levels of adherence to ICS were associated with a reduced risk of severe asthma exacerbations in children, ${ }^{17}$ but increasing evidence exists that the relation between adherence to ICS and the occurrence of exacerbations is less straight forward than we used to think. Several studies reported a reverse association between adherence and risk of severe asthma exacerbations. ${ }^{18-21}$ Rust et al, ${ }^{22}$ for example, found that $1.9 \%$ of children with refill adherence to ICS $<50 \%$ had a hospital admission for asthma versus $3.2 \%$ of children with refill rate $>50 \%(P<0.01)$. In another study, patients reduced their prescribed controller medication without negative consequences, ${ }^{23}$ whereas other patients continued to have poor outcomes despite good adherence. ${ }^{24}$ Apart from the heterogeneity of the study results, all studies failed to address an essential methodological issue, being the temporal relation between (non-)adherence to ICS use and the asthma exacerbations. The former should precede the latter; otherwise, a causal relationship between both variables is not plausible.

To overcome this methodological issue, we designed a study into the temporal relation between adherence to ICS and the incidence of asthma exacerbations in children in a general real-life population of children with asthma. The aim of our study was to measure refill adherence to ICS in children with asthma aged 5-12 years, and to study its association with the frequency of asthma exacerbations needing a short course of oral corticosteroids or a hospital admission. Our hypothesis was that good refill adherence would be associated with a reduced risk of severe asthma exacerbations.

\section{Methods}

\section{Setting}

In this nested case-control study, a cohort of 150,000 patients was randomly selected from a subset of the PHARMO Record Linkage System (RLS). The PHARMO RLS contains medication-dispensing records from community pharmacies linked to hospital discharge records of more than two million inhabitants of the Netherlands. The computerized drug-dispensing histories contained detailed data about the dispensed medicines, dosing regimens, and type of prescriber. The hospital records included detailed information on primary and secondary diagnoses, procedures, and dates of hospital admission and discharge. All diagnoses were coded according to the International Classification of Diseases (ICD), 9th Revision, Clinical Modification. ${ }^{25}$

The privacy regulation of the PHARMO institute was approved by the Dutch Data Protection Authority. According to the Dutch legislation, neither obtaining informed consent nor approval by a medical ethics committee is obligatory for database studies without direct patient involvement. ${ }^{26}$ Hence, formal consent is not required for this retrospective, anonymized database study.

\section{Study population}

The study population included all children who were $\geq 5$ and $\leq 12$ years of age on the cohort entry date and had filled their first prescription of ICS between 1998 and 2008. Its dispensing date was considered the cohort entry date. The following types of ICS or combinations with beta-agonists were allowed: beclomethasone, budesonide, fluticasone, ciclesonide, salmeterol/fluticasone, and formoterol/budesonide. Patients were included if they did not use ICS in the 1 year preceding the cohort entry date. Patients had to be registered in the PHARMO database for at least 1 year before and 1 year after the cohort entry date. Patients taking ICS using a nebulizer were excluded from the cohort.

\section{Outcome measures}

Severe asthma exacerbations, requiring admission to hospital or a short course of oral corticosteroids, were used as primary outcome measure. The date of the exacerbation was called the "index date". In the hospital discharge records, patients discharged with ICD-code 493 (asthma) or ICD-code 786.07 (wheezing) were counted as asthma-related admissions to hospital. Short courses of oral corticosteroid use were identified from drug-dispensing records as episodes of oral corticosteroid use (Anatomical Therapeutic Chemical code: 
$\mathrm{H} 02 \mathrm{AB}$ ) of not $>15$ days. ${ }^{2}$ Incorrectly registered (eg, double) corticosteroid medication records, and records of oral corticosteroids not prescribed by a general practitioner, pediatrician, or pulmonologist were not considered.

Asthma exacerbations were not included: 1) if the cohort entry date was $<3$ months before the index date, as this observation period is too short to calculate a reliable measure for refill adherence; 2) if a previous event had occurred $<12$ months before the event date, as both events may not be independent; and 3) if there were less than two ICS prescriptions in the year prior to the index date, since no reliable calculation of refill adherence is then possible.

\section{Determinants}

The primary determinant in our study, that is, refill adherence to ICS, was calculated as the medication possession ratio (MPR). First, all ICS dispenses were converted into treatment episodes of consecutive use of ICS following the method of Catalan and Lelorier. ${ }^{27}$ Switches from one to another type of ICS and changes in dose regimen were allowed. If possible, atypical ICS episodes caused by incorrect registration of medication records were corrected; otherwise, patients were excluded. The refill adherence was calculated as the ratio of the number of daily ICS dosages dispensed and the number of days in the episode ${ }^{28}$ for a period of 12 months preceding the index date.

The following co-variables were included: Sex and age were noted at cohort entry date. At index date, age, type of ICS, type of prescriber of ICS, type of inhaler, daily dose, dosing frequency of ICS, and time from cohort entry date to index date were obtained. Finally, we collected the number of dispenses of co-medications within 3 months and within 12 months before the index date.

\section{Matching cases and controls}

Patients who had an asthma exacerbation (cases) were matched with control patients who at that moment had the same age $( \pm 1$ year) and had no asthma exacerbation in the previous 12 months (incidence density sampling). Under the condition that there had not been a previous asthma exacerbation in the preceding 12 months, cases could also be analyzed as control patients, and control patients could be analyzed more than once at different moments in follow-up. For this reason, the results of this study were reported as number of "event moments" (with exacerbation) and matched "control moments" (without exacerbation) instead of "cases" and "control patients". It is noted that control moments (without exacerbations) could originate both from patients with exacerbations and from patients without.

\section{Data analysis}

Using the approach of Dupont ${ }^{29}$ and software "PS Power and Sample Size Calculations", ${ }^{30}$ we determined the sample size required to detect a twofold, 2.5-fold, or threefold increase in risk of asthma exacerbation between ICS adherence $\geq 80 \%$ and $<80 \%$ with 0.8 power at the 0.05 significance level. Assuming that each case is matched with minimal 30 controls, the probability of ICS adherence $\geq 80 \%$ among controls is 0.2 , and the correlation coefficient for ICS adherence between matched cases and controls is 0.2 ; the required sample size is 88,48 , or 32 case patients with 30 matched control(s) per case.

A multiplicative intensity model was applied to assess the effect of refill adherence to ICS on the occurrence of asthma exacerbations, using statistical software " $R$ " (version 2.15.2, Vienna, Austria) with library "survival". ${ }^{31}$ The multiplicative intensity model was introduced by Aalen in $1978^{32}$ and is a generalization of Cox proportional hazards regression for multiple recurrent events per subject, time-dependent covariates, left truncated and left censored data, and calendar timescale.

Co-variables that showed (borderline) statistical significance $(P<0.1)$ in the univariable analysis were investigated for confounding by adding them to the statistical model and leaving them in the model if the regression coefficient changed by $>10 \%$.

The following co-variables were investigated for effect modification of the association of adherence with asthma exacerbations: recent use of SABA or short-acting muscarinic antagonists, both as a measure of asthma control; recent use of long-acting beta-agonist (LABA), as a measure of asthma severity; and recent use of systemic antibiotics, since asthma exacerbations are often triggered by respiratory infections. These potential effect modifiers were investigated by adding the interaction term to the statistical model; if its regression coefficient was significantly $>0.0(P<0.05)$, the parameter was considered an effect modifier.

\section{Results}

A total of 934 children matched the inclusion criteria, and 646 children also met the requirements for correct calculation of refill adherence (Figure 1). In this final study population, 365 (57\%) children were male, and the mean age was 8.1 years (standard deviation [SD] 2.2) at cohort entry date and 9.6 years (SD 2.1) at index date. 


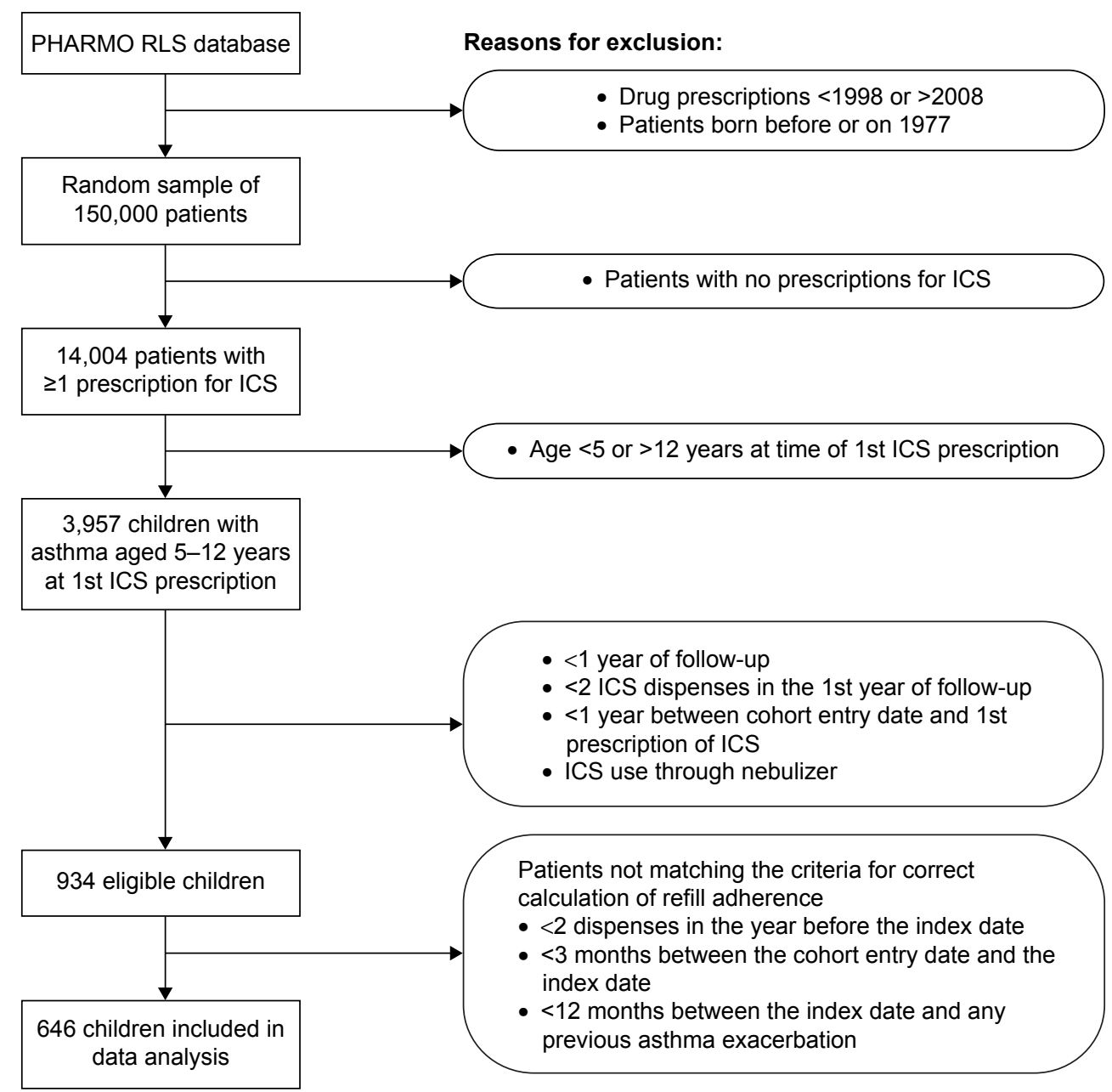

Figure I Flowchart for patient selection.

Abbreviations: PHARMO RLS, PHARMO Record Linkage System; ICS, inhaled corticosteroid.

The frequency of recent use of SABA, LABA, combined ICS and LABA, nasal decongestants, and systemic antibiotics differed significantly between event moments (with an asthma exacerbation) and control moments (without exacerbations) (Table 1). The use of asthma medication not reported in Table 1 was negligibly low in the 12 months preceding the events.

A total of 40 asthma exacerbations in 36 patients were included in the analysis: 32 short courses of oral corticosteroids and eight hospital admissions for asthma. The incidence density rate of asthma exacerbations needing hospital admission was 8.1/1,000 patient-years, and 43.8/1,000 patientyears for short courses of oral corticosteroids. Asthma exacerbations were matched to 1,596 control moments without an event with a mean of 42 control moments per stratum (range: 4-72).

The mean MPR for ICS was $67.9 \%$ (SD 30.2\%) in the 12 months before the event moments versus $54.2 \%$ (SD $35.6 \%$ ) for the control moments. The proportion of patient moments with MPR $\geq 80 \%$ was $35.0 \%$ (SD 48.3) for event moments and $20.2 \%$ (SD 40.1) for control moments (Table 2).

Recent LABA use, within 3 months before the index date, was identified as an effect modifier. Therefore, data were stratified, and two separate models were presented (Table 3). In the non-LABA stratum, the intensity ratio of asthma exacerbations was 1.07 (95\% confidence interval [CI]: 0.39-2.92) for refill adherence to ICS $\geq 80 \%$ and 4.34 (95\% CI: 1.20-15.64) in patients with recent LABA use, both adjusted for recent SABA use (within 3 months before the index date) as the only confounder.

\section{Discussion}

In children with persistent asthma needing the use of LABA, we found that good refill adherence to ICS was associated with an increased risk of asthma exacerbations. No association was found in children not using LABA. 
Table I Characteristics of analyzed patient moments

\begin{tabular}{|c|c|c|c|c|}
\hline Variable & Categories/details & $\begin{array}{l}\text { Event moments } \\
\text { (with asthma } \\
\text { exacerbation) }(n=40)\end{array}$ & $\begin{array}{l}\text { Control moments } \\
\text { (without exacerbation) } \\
(n=1,596)\end{array}$ & $P$-value ${ }^{a}$ \\
\hline \multirow[t]{3}{*}{ Type of ICS, N (\%) } & Fluticasone & $30(75.0)$ & $\mathrm{I}, \mathrm{I} 27(70.6)$ & 0.613 \\
\hline & Beclomethasone & $3(7.5)$ & $283(17.7)$ & \\
\hline & Budesonide & $7(17.5)$ & $186(11.6)$ & \\
\hline ICS dose, mean (SD) & $\begin{array}{l}\text { Proportion of the } \\
\text { defined daily dose }\end{array}$ & $0.60(0.36)$ & $0.57(0.67)$ & 0.650 \\
\hline \multirow[t]{6}{*}{ Dosing frequency ICS, N (\%) } & I time a day & I (2.5) & $78(4.9)$ & 0.497 \\
\hline & I-2 times a day & $0(0.0)$ & $16(1.0)$ & \\
\hline & 2 times a day & $38(95.0)$ & $\mathrm{I}, 440(9 \mathrm{I} .3)$ & \\
\hline & $2-3$ times & $0(0.0)$ & $2(0.1)$ & \\
\hline & 3 times a day & I (2.5) & $36(2.3)$ & \\
\hline & 4 times a day & $0(0.0)$ & $5(0.3)$ & \\
\hline $\begin{array}{l}\text { Time from cohort entry to index date, } \\
\text { mean (SD) }\end{array}$ & Years & $\mathrm{I} .87(\mathrm{I} .4 \mathrm{I})$ & $1.80(1.29)$ & 0.184 \\
\hline \multirow[t]{3}{*}{ Type of inhaler, N (\%) } & pMDI & $23(57.5)$ & $878(55.0)$ & 0.938 \\
\hline & Extrafine particle pMDI & I (2.5) & $31(1.9)$ & \\
\hline & DPI & $16(40.0)$ & $687(43.0)$ & \\
\hline \multirow{4}{*}{ Prescriber, N (\%) } & General practitioner & $28(70.0)$ & $1,310(82.1)$ & 0.134 \\
\hline & Pediatrician & $10(25.0)$ & $238(14.9)$ & \\
\hline & Pulmonologist & $2(5.0)$ & $33(2.1)$ & \\
\hline & Other & $0(0.0)$ & $15(0.9)$ & \\
\hline SABA, number of Rx preceding the index & SABA 12 months & $2.9(2.0)$ & $\mathrm{I} .8(2.0)$ & 0.002 \\
\hline date, mean (SD) & SABA 3 months & $\mathrm{I} .3(\mathrm{I} .4)$ & $0.6(1.0)$ & 0.001 \\
\hline LABA, number of Rx preceding the index & LABA I 2 months & $1.5(2.5)$ & $0.8(1.8)$ & 0.004 \\
\hline date, mean (SD) & LABA 3 months & $0.6(1.0)$ & $0.3(0.8)$ & 0.013 \\
\hline Combined LABA and ICS, number of Rx & LABA + ICS 12 months & $1.3(2.3)$ & $0.7(1.7)$ & 0.015 \\
\hline preceding the index date, mean (SD) & LABA + ICS 3 months & $0.5(0.9)$ & $0.3(0.7)$ & 0.030 \\
\hline SAMA, patient moments with $\geq I \mathrm{Rx}$ & SAMA 12 months & $2(5)$ & $12(0.8)$ & $\mathrm{NA}^{\mathrm{b}}$ \\
\hline preceding the index date, $\mathrm{N}(\%)$ & SAMA 3 months & $2(5)$ & $4(0.3)$ & \\
\hline Leukotriene antagonists, patient & Montelukast & $3(7.5)$ & $69(4.3)$ & $\mathrm{NA}^{\mathrm{b}}$ \\
\hline moments with $\geq I$ Rx preceding the & 12 months & & & \\
\hline index date, $\mathrm{N}(\%)$ & Montelukast 3 months & $\mathrm{I}(2.5)$ & $53(3.3)$ & \\
\hline Antihistaminergic agents, number of $\mathrm{Rx}$ & AHIST I 2 months & $0.9(1.5)$ & $0.5(1.2)$ & 0.050 \\
\hline preceding the index date, mean (SD) & AHIST 3 months & $0.2(0.6)$ & $0.1(0.5)$ & 0.240 \\
\hline Nasal decongestants, number of Rx & Xylomethazoline & $0.9(1.4)$ & $0.7(1.4)$ & 0.364 \\
\hline \multirow[t]{3}{*}{ preceding the index date, mean (SD) } & 12 months & & & \\
\hline & Xylomethazoline & $0.6(0.9)$ & $0.3(0.7)$ & 0.020 \\
\hline & 3 months & & & \\
\hline Systemic antibiotics, number of $\mathrm{Rx}$ & Antibiotics 12 months & $1.2(1.4)$ & $0.7(1.3)$ & 0.024 \\
\hline preceding the index date, mean (SD) & Antibiotics 3 months & $0.2(0.4)$ & $0.1(0.5)$ & 0.337 \\
\hline Systemic corticosteroid use $>15$ days, & SCS I 2 months & $\mathrm{I}(2.5)$ & $6(0.4)$ & $N A^{b}$ \\
\hline $\begin{array}{l}\text { patient moments with } \geq \text { I Rx preceding } \\
\text { the index date, } N(\%)\end{array}$ & SCS 3 months & $0(0.0)$ & $3(0.2)$ & \\
\hline
\end{tabular}

Notes: aAnalyzed with a multiplicative intensity model. b Not enough data for statistical testing.

Abbreviations: ICS, inhaled corticosteroid; SD, standard deviation; pMDI, pressurized metered dose inhaler; DPI, dry powder inhaler; SABA, short-acting beta-agonist; Rx, prescription; LABA, long-acting beta-agonist; SAMA, short-acting muscarinic antagonist; NA, not available; AHIST, antihistaminergic agent; SCS, systemic corticosteroid.

Therefore, we rejected our hypothesis that good refill adherence was associated with a reduced risk of severe asthma exacerbations.

These results contrast to earlier findings in which high adherence to ICS was associated with good improved asthma control $^{15,33}$ and with a reduced risk of asthma exacerbations. ${ }^{17}$ Only a few earlier studies reported a reverse association. ${ }^{18-21}$
A possible explanation for the higher observed level of adherence in children with exacerbations is that the children with exacerbations had a lower level of asthma control to start with, which would have motivated them to take their ICS more adherently. Poorly controlled asthma would therefore be associated with higher adherence rates. In answer to the question why higher levels of adherence not necessarily lead 
Table 2 Refill adherence to ICS in all children, in children with recent LABA use, and in children without recent LABA use

\begin{tabular}{|c|c|c|}
\hline Adherence measures & $\begin{array}{l}\text { Event moments (with asthma } \\
\text { exacerbation) }\end{array}$ & $\begin{array}{l}\text { Control moments (without asthma } \\
\text { exacerbation) }\end{array}$ \\
\hline All children, $n=1,636$ & $n=40$ & $n=1,596$ \\
\hline Refill adherence to ICS, mean (SD) (IQR, \%) & $67.9(30.2)(49.6 ; 87.5)$ & $54.2(35.6)(28.5 ; 71.2)$ \\
\hline Refill adherence to ICS $\geq 80 \%, \mathrm{n}(\%)$ & $14(35.0)$ & $322(20.2)$ \\
\hline No recent LABA use $n=I, 342$ & $\mathbf{n}=\mathbf{2 7}$ & $n=I, 3 \mid 5$ \\
\hline Refill adherence to ICS, mean (SD) (IQR, \%) & $60.3(28.9)(44.8 ; 72.6)$ & $51.3(35.8)(27.5 ; 65.6)$ \\
\hline Refill adherence to ICS $\geq 80 \%, n$ (\%) & $5(18.5)$ & $226(17.2)$ \\
\hline Recent LABA use, $n=294$ & $n=13$ & $\mathbf{n}=\mathbf{2 8} \mathbf{I}$ \\
\hline Refill adherence to ICS, mean (SD) (IQR, \%) & $83.8(27.4)(72.6 ; 102.6)$ & 67.7 (31.6) (44.3; 86.5) \\
\hline Refill adherence to ICS $\geq 80 \%, n$ (\%) & $9(69.2)$ & $96(34.1)$ \\
\hline
\end{tabular}

Abbreviations: ICS, inhaled corticosteroid; LABA, long-acting beta-agonist; SD, standard deviation; IQR, interquartile range.

to better asthma control and to less asthma exacerbations, Klok et al hypothesized that the minimum level of adherence needed for achieving asthma control is higher in patients with ongoing persistent asthma, than in patients with asthma in clinical remission. ${ }^{16}$ Patients in the latter group, who are easily overtreated with ICS, would maintain asthma control at a lower level of adherence than the former.

In our study, recent LABA use, as a proxy for asthma severity, was identified as an effect modifier. Good adherence to ICS was only associated with a higher risk of asthma exacerbations in children with more severe asthma (needing the use of LABA). Apparently, the intake of ICS was less critical for maintaining asthma control in children with less severe asthma. As a result, these children were possibly less motivated for taking ICS adherently.

A strength of this study is our large patient sample ( $n=934)$ and long follow-up period (10 years). Also, contrary to earlier studies that used pharmacy data, ${ }^{34,35}$ we limited the refill-adherence calculation to the period immediately preceding the asthma exacerbation. Regarding the limited biological half-life of ICS, it is considered unlikely that non-adherence to ICS leads to the occurrence of an asthma exacerbation $>12$ months in the future. Our approach also ruled out the effect of ICS test doses and short episodes of ICS use after the occurrence of an exacerbation or pulmonary infection, which may otherwise bias adherence calculation. Another strength is that pharmacy records were combined with hospital discharge data, so that both asthma exacerbations treated with a short course of oral corticosteroids and those needing hospital admission could be included into the analysis.

A limitation of our study is that the use of pharmacy record data tends to overestimate the actual medication adherence. In one of the sparse studies evaluating the magnitude of this overestimation, a 9\% difference was found between refill adherence and electronically measured dose count. ${ }^{36}$ This overestimation seems too small to explain why we have found a higher adherence rate in children with an exacerbation. Another potential source of overestimation of adherence to ICS was our inclusion criterion that demanded a minimum of two ICS dispenses in the 12 months before the index date. This criterion was introduced to ensure valid MPR calculation (ie, limited discontinuation of ICS use). However, our sensitivity analysis with the inclusion criterion of at least one ICS dispensing in the preceding 12 months showed a similar association between adherence and exacerbations (data not reported). Like most patient databases, PHARMO RSL does not contain detailed data on asthma control. We have dealt with this issue by using recent SABA use as a proxy for asthma control, but this is only one out

Table 3 Association of refill adherence to ICS with the intensity of asthma exacerbations in children using LABA and in children not using LABA

\begin{tabular}{|c|c|c|}
\hline \multirow[t]{2}{*}{ Adherence measures } & \multicolumn{2}{|c|}{ Intensity ratio of exacerbations $(95 \% \mathrm{Cl})$} \\
\hline & Univariable & Multivariable $^{a}$ \\
\hline \multicolumn{3}{|l|}{ No recent $L A B A$ use, $n=I, 342$} \\
\hline Adherence to $\mathrm{ICS} \geq 80 \%^{\mathrm{b}}$ & 1.270 (0.47I; $3.4 \mid 9) ; P=0.637$ & 1.067 (0.39I; 2.916$) ; P=0.899$ \\
\hline \multicolumn{3}{|l|}{ Recent LABA use, $n=294$} \\
\hline Adherence to ICS $\geq 80 \%$ b & 4.459 (I.287; I5.454); $P=0.018$ & $4.340(\mathrm{I} .204 ; \mathrm{I} 5.640) ; P=0.025$ \\
\hline
\end{tabular}

Notes: aAdjusted for confounding by recent SABA use. ${ }^{\mathrm{b}}$ Refill adherence to inhaled corticosteroids.

Abbreviations: ICS, inhaled corticosteroid; LABA, long-acting beta-agonist; SABA, short-acting beta-agonist; $\mathrm{Cl}$, confidence interval. 
of three GINA indicators for asthma control. ${ }^{2}$ It can also not be ruled out that asthma exacerbations needing a short course of oral corticosteroids were missed if patients used oral corticosteroids as chronic treatment. This is unlikely to change the study results, since the chronic use of systemic corticosteroids was rare $(0.4 \%)$ in this study. In addition, asthma exacerbations that were treated with only a temporary increased ICS dose might have remained undetected in our study. These mild asthma exacerbations, however, were outside the scope of our study, since we focused on severe asthma exacerbations. A final limitation of our database study is that it required a highly developed Information and Communication Technology infrastructure for administering pharmacy records and hospital discharge data. This may be an obstacle for researchers trying to reproduce the results of our study in regions where this infrastructure is lacking.

Based on the results of this study, clinicians treating children with asthma should be aware of the complex relation between adherence to ICS and asthma control. Patients having an asthma exacerbation often have good adherence to ICS, while other patients with poor adherence to ICS do not suffer any clinical consequences. The former phenomenon may involve patients who self-manage their ICS therapy according to, for example, their current asthma control or disease burden. We think that the latter is likely to be caused by overprescription of ICS, in case of which stepwise dose reductions or even discontinuation of ICS therapy may be required.

In future research, prospective studies using objective measures are needed to further assess the complex relation between asthma control and adherence to ICS, both in children who are in clinical remission and in children with unstable asthma. This would require longitudinal cohort studies in which objective adherence measures such as electronic medication monitoring are used, and in which important potential confounders, like asthma control, are taken into account. However, this would require costly electronic monitoring, long follow-up periods, and large study samples (considering the generally low incidence of severe asthma exacerbations). In order to avoid bias by overprescription of ICS or patient-initiated dose adjustments and interruptions, we suggest a study approach in which, prior to the study, ICS doses are titrated to the lowest levels on which asthma control is just maintained. This would enhance the clinical impact of non-adherence to ICS, providing a clearer view on the complex association of adherence to ICS with asthma control and the risk of asthma exacerbations.

\section{Conclusion}

In children with persistent asthma who also used LABA, adherence to ICS was associated with an increased risk of asthma exacerbations. No association was found in children not using LABA. Prospective studies into the complex relation between adherence to ICS and asthma control are needed.

\section{Disclosure}

Patricia MLA van den Bemt has received an unconditional research grant from the Dutch government (ZonMw) and from GlaxoSmithKline for a different, investigator-initiated study on medication adherence in children with asthma. Liset van Dijk has received unrestricted grants from Astra Zeneca, Bristol-Myers Squibb, and Pfizer for studies not related to this study. The other authors report no conflicts of interest in this work.

\section{References}

1. Masoli M, Fabian D, Holt S, Beasley R. Global Initiative for Asthma (GINA) Program. The global burden of asthma: executive summary of the GINA Dissemination Committee report. Allergy. 2004;59(5): 469-478.

2. GINA. Global strategy for asthma management and prevention. Global Initiative for Asthma (GINA); 2015. Available from: http://www. ginasthma.org/. Accessed December 29, 2015.

3. Sin DD, Man J, Sharpe H, Gan WQ, Man SFP. Pharmacological management to reduce exacerbations in adults with asthma - a systematic review and meta-analysis. JAMA. 2004;292(3):367-376.

4. Hammer SC, Robroeks CMHHT, van Rij C, et al. Actual asthma control in a paediatric outpatient clinic population: do patients perceive their actual level of control? Pediatr Allergy Immunol. 2008;19(7): 626-633.

5. McConnochie KM, Russo MJ, McBride JT, Szilagyi PG, Brooks AM, Roghmann KJ. Socioeconomic variation in asthma hospitalization: excess utilization or greater need? Pediatrics. 1999;103(6):e75.

6. Johnston NW, Sears MR. Asthma exacerbations. 1: epidemiology. Thorax. 2006;61(8):722-728.

7. Lieu TA, Lozano P, Finkelstein JA, et al. Racial/ethnic variation in asthma status and management practices among children in managed medicaid. Pediatrics. 2002;109(5):857-865.

8. Thakur N, Martin M, Castellanos E, et al. Socioeconomic status and asthma control in African American youth in SAGE II. $J$ Asthma. 2014;51(7):720-728.

9. Kopel LS, Phipatanakul W, Gaffin JM. Social disadvantage and asthma control in children. Paediatr Respir Rev. 2014;15(3):256-262.

10. Zahran HS, Bailey CM, Qin X, Moorman JE. Assessing asthma severity among children and adults with current asthma. J Asthma. 2014;51(6):610-617.

11. Klok T, Kaptein AA, Duiverman EJ, Brand PL. High inhaled corticosteroids adherence in childhood asthma: the role of medication beliefs Eur Respir J. 2012;40(5):1149-1155.

12. Bender B, Wamboldt FS, O'Connor SL, et al. Measurement of children's asthma medication adherence by self report, mother report, canister weight, and Doser CT. Ann Allergy Asthma Immunol. 2000;85(5): 416-421.

13. Vasbinder E, Dahhan N, Wolf B, et al. The association of ethnicity with electronically measured adherence to inhaled corticosteroids in children. Eur J Clin Pharmacol. 2013;69(3):683-690. 
14. Celano M, Geller RJ, Phillips KM, Ziman R. Treatment adherence among low-income children with asthma. J Pediatr Psychol. 1998; 23(6):345-349.

15. Jentzsch NS, Camargos P, Sarinho ES, Bousquet J. Adherence rate to beclomethasone dipropionate and the level of asthma control. Respir Med. 2012;106(3):338-343.

16. Klok T, Kaptein AA, Duiverman EJ, Brand PL. It's the adherence, stupid (that determines asthma control in preschool children)! Eur Respir J. 2014;43(3):783-791.

17. Engelkes M, Janssens HM, De Jongste JC, Sturkenboom MCJM, Verhamme KMC. Medication adherence and the risk of severe asthma exacerbations: a systematic review. Eur Respir J. 2015;45(2): 396-407.

18. Price D, Thomas M, Haughney J, et al. Real-life comparison of beclometasone dipropionate as an extrafine- or larger-particle formulation for asthma. Respir Med. 2013;107(7):987-1000.

19. McMahon AD, Lipworth BJ, Davey PG, Morris AD, Macdonald TM. Continuity of prescribing with inhaled corticosteroids and control of asthma. Pharmacoepidemiol Drug Saf. 2000;9(4):293-303.

20. Smith K, Warholak T, Armstrong E, Leib M, Rehfeld R, Malone D. Evaluation of risk factors and health outcomes among persons with asthma. J Asthma. 2009;46(3):234-237.

21. Osman LM, Friend JA, Legge JS, Douglas JG. Requests for repeat medication prescriptions and frequency of acute episodes in asthma patients. J Asthma. 1999;36(5):449-457.

22. Rust G, Zhang S, Reynolds J. Inhaled corticosteroid adherence and emergency department utilization among Medicaid-enrolled children with asthma. J Asthma. 2013;50(7):769-775.

23. Riekert KA, Butz AM, Eggleston PA, Huss K, Winkelstein M, Rand CS. Caregiver-physician medication concordance and undertreatment of asthma among inner-city children. Pediatrics. 2003;111(3): e214-e220.

24. Smyth AR, Barbato A, Beydon N, et al. Respiratory medicines for children: current evidence, unlicensed use and research priorities. Eur Respir J. 2010;35(2):247-265.

25. Breekveldt-Postma NS, Erkens JA, Aalbers R, de Ven MJTV, Lammers JWJ, Herings RMC. Extent of uncontrolled disease and associated medical costs in severe asthma - a PHARMO study. Curr Med Res Opin. 2008;24(4):975-983.
26. Breekveldt-Postma NS, Koerselman J, Erkens JA, et al. Treatment with inhaled corticosteroids in asthma is too often discontinued. Pharmacoepidemiol Drug Saf. 2008;17(4):411-422.

27. Catalan VS, Lelorier J. Predictors of long-term persistence on statins in a subsidized clinical population. Value Health. 2000;3(6):417-426.

28. Andrade SE, Kahler KH, Frech F, Chan KA. Methods for evaluation of medication adherence and persistence using automated databases. Pharmacoepidemiol Drug Saf. 2006;15(8):565-574.

29. Dupont WD. Power calculations for matched case control studies. Biometrics. 1988;44(4):1157-1168.

30. Dupont WD, Plummer WD. Power and sample size calculations: a review and computer program. Controlled Clinical Trials. 1990;11: 116-128.

31. Andersen PK, Borgan Ø, Gill RD, Keiding N. Statistical Models Based on Counting Processes, Springer Series in Statistics. New York: Springer-Verlag; 1993

32. Aalen OO. Non-parametric inference for a family of counting processes. Ann Statist. 1978;6:701-726.

33. Koster ES, Raaijmakers JAM, Vijverberg SJH, Maitland-van der Zee AH. Inhaled corticosteroid adherence in paediatric patients: the PACMAN cohort study. Pharmacoepidemiol Drug Saf. 2011; 20(10):1064-1072.

34. Lasmar L, Camargos P, Champs NS, et al. Adherence rate to inhaled corticosteroids and their impact on asthma control. Allergy. 2009;64(5): 784-789.

35. Milgrom H, Bender B, Ackerson L, Bowry P, Smith B, Rand C. Noncompliance and treatment failure in children with asthma. J Allergy Clin Immunol. 1996;98(6 Pt 1):1051-1057.

36. Choo PW, Rand CS, Inui TS, et al. Validation of patient reports, automated pharmacy records, and pill counts with electronic monitoring of adherence to antihypertensive therapy. Med Care. 1999;37(9):846-857.
Patient Preference and Adherence

\section{Publish your work in this journal}

Patient Preference and Adherence is an international, peer-reviewed, open access journal that focuses on the growing importance of patient preference and adherence throughout the therapeutic continuum. Patient satisfaction, acceptability, quality of life, compliance, persistence and their role in developing new therapeutic modalities and compounds to optimize

\section{Dovepress}

clinical outcomes for existing disease states are major areas of interest for the journal. This journal has been accepted for indexing on PubMed Central. The manuscript management system is completely online and includes a very quick and fair peer-review system, which is all easy to use. Visit http://www. dovepress.com/testimonials.php to read real quotes from published authors. 